\title{
Indigenous Research in the Days of COVID-19 in Pakistan
}

\section{Ahmad Bilal ${ }^{1}$}

${ }^{1}$ Managing Editor, Journal of Professional \& Applied Psychology

It gives us immense pleasure in announcing the completion of $1^{\text {st }}$ volume of Journal of Professional \& Applied Psychology by publishing the $2^{\text {nd }}$ issue. The $2^{\text {nd }}$ issue contains original articles on issues of indigenous importance. The importance of indigenous research in psychological sciences cannot be underestimated. The Pakistani society is ever changing and facing a number of psychological issues. The indigenous research may provide an empirical approach towards understanding and improving the problems of local nature. There are hundreds of students graduating in psychology each year in Pakistan. Their indigenous research needs dissemination, thus providing a channel for change and growth.

The journal is multidisciplinary in nature accepting manuscripts relating to any field focusing any psychological aspect of professional, applied, or basic nature. Moreover, the journal believes in publishing studies with negative results or replication studies to encourage the young journal authors, thus, allowing the publication of foreign ideas in local context.

The Journal of Professional \& Applied Psychology follows an open access model of publication which allows the easy and free access to published scientific material. The journal's open access policy is free of charge and contribute to the timely dissemination of scientific work in the field of multidisciplinary psychology. All published articles are available permanently for free on journal website.

The journal management hopes to make agreements with conference bodies to publish special issues containing the conference full papers, thus making the dissemination of indigenous research more easy and speedy. The ease and speed of publication of articles is the primary focus of the journal management. The journal is first Pakistani psychology journal featuring the dates of receiving and accepting the article, thereby, making the whole publication process transparent. Moreover, the journal uses the Open Journal Systems (OJS) platform of Public Knowledge Project (PKP) which allows users to track the progress of their submitted work. The journal management hope to enhance the speed of review and publication significantly.

The journal publication is not without its costs. Finding the dedicated and committed reviewers and making them respond in a timely manner is the real success of editorial board of a journal. In Pakistan, people generally prefer to publish in HEC recognized journals. There is a set criteria of getting HEC recognition for a local journal. A journal has to go through each of the criteria to get recognition. To get people submit an article and making reviewers respond to editorial board's requests is a daunting task.

Reviewing for an academic journal not only improves one's skills and knowledge rather contributes towards the scientific publishing process. The journal is in the process of developing incentives for reviewers. The role and responsibilities of reviewers, and authors have been changed due to change in daily routines owing to global pandemic (COVID19). The journal management is aware of

This article is distributed under the terms of the Creative Commons Attribution Non Commercial 4.0 License (http://www.creativecommons.org/licenses/by-nc/4.0/) which permits nonCommercial use, reproduction and distribution of the work without further permission provided the original work is attributed as specified. 
these difficult circumstances and hopes for a normal routine in the future.

The journal will complete its $2^{\text {nd }}$ volume during 2021. The current issue will herald the dawn of a new year, 2021 which will bring new horizons for indigenous research owing to ever changing international and national scenarios. The journal is making its journey towards applying for HEC recognition first, and going for international recognition, later, hopefully.

I hope, you will find the articles in the current issue both informative and interesting leaving you with new insights into psychological knowledge and practices.

Welcome to the $2^{\text {nd }}$ issue of $1^{\text {st }}$ volume of Journal of Professional \& Applied Psychology! Happy Reading! 